\title{
O ensino de ciências da natureza durante a pandemia da Covid-19: desafios e possibilidades nas redes pública e privada
}

\author{
The teaching of nature sciences during the pandemic of Covid-19: challenges and possibilities in
} public and private schools

\author{
La enseñanza de las ciencias de la naturaleza durante la pandemia del Covid-19: desafíos y \\ posibilidades en las escuelas públicas y privadas
}

\section{Resumo}

Introdução: A pandemia da Covid-19 interferiu diretamente na educação escolar, onde educadores e alunos tiveram que se reinventar a partir do momento em que as escolas fecharam suas portas para o ensino presencial. Neste sentido, a tecnologia tem um papel importante para minimizar os impactos vivenciados durante a pandemia. Objetivo: analisar as concepções dos docentes acerca do ensino de Ciências da Natureza e suas dificuldades para o processo de ensino em sala de aula, e da análise de aulas práticas em tempos remotos como ferramentas de assimilação de conteúdos e se as mesmas contribuíram de forma relevante no processo ensino-aprendizagem dos alunos na pandemia Metodologia: esse trabalho foi desenvolvido com professores da área de ciências da natureza atuantes na educação básica de duas escolas, sendo uma escola pública, do estado de Pernambuco e uma escola particular do estado de Minas Gerais. Considerações: É preciso investir na formação inicial e continuada dos professores da educação básica, em prol do melhor preparo para o trabalho docente na atualidade. É de extrema importância o investimento em políticas públicas voltadas para esse tipo de formação, bem como no melhor amparo tecnológico da referida classe, e para os alunos, que também necessitam estar aprofundados e preparados para um possível evento que permita o distanciamento social.

Palavras-chave: Pandemia; Ensino; Ciências da natureza; Educação básica.

\begin{abstract}
Introduction: The Covid-19 pandemic directly interfered in school education, where educators and students had to reinvent themselves from the moment schools closed their doors to face-to-face teaching. In this sense, technology plays an important role in minimizing the impacts experienced during the pandemic. Objective: analyze the teachers' conceptions about the teaching of Natural Sciences and their difficulties for the classroom teaching process, and the analysis of practical classes in remote times as tools for assimilating content and whether they contributed in a relevant way in the teaching-learning process of students in the pandemic. Methodology: this work was carried out with teachers in the area of natural sciences working in basic education at two schools, being a public school in the state of Pernambuco and a private school in the state of Minas Gerais. Considerations: It is necessary to invest in initial and continuing training of basic education teachers, in favor of better preparation for teaching work today. It is extremely important to invest in public policies aimed at this type of training, as well as in the best technological support for that class, and for the students, who also need to be in-depth and prepared for a possible event that allows for social distancing.
\end{abstract}

Keywords: Pandemic; Teaching; Natural Sciences; Basic Education. 


\begin{abstract}
Resumen
Introducción: La pandemia Covid-19 interfirió directamente en la educación escolar, donde los educadores y estudiantes tuvieron que reinventarse desde el momento en que las escuelas cerraron sus puertas a la enseñanza presencial. En este sentido, la tecnología juega un papel importante en la minimización de los impactos experimentados durante la pandemia. Objetivo: analizar las concepciones de los docentes sobre la enseñanza de las Ciencias Naturales y sus dificultades para el proceso de enseñanza en el aula, y el análisis de las clases prácticas en tiempos remotos como herramientas de asimilación de contenidos y si contribuyeron de manera relevante en la enseñanza. proceso de aprendizaje de los estudiantes en la pandemia Metodología: este trabajo se llevó a cabo con docentes en el campo de las ciencias naturales que trabajan en educación básica en dos escuelas, una escuela pública en el estado de Pernambuco y una escuela privada en el estado de Minas Gerais. Consideraciones: Es necesario invertir en la formación inicial y continua de los docentes de educación básica, en pro de una mejor preparación para la labor docente actual. Es sumamente importante invertir en políticas públicas orientadas a este tipo de formación, así como en el mejor soporte tecnológico para la clase mencionada, y para los estudiantes, quienes también necesitan estar en profundidad y preparados para un posible evento que permita distancia social.
\end{abstract}

Palabras clave: Pandemia; Enseñando; Ciencias de la naturaleza; Educación básica.

\title{
1. Introdução
}

Em janeiro de 2020, a OMS (Organização Mundial da Saúde) alertou para o surgimento de um novo vírus que se espalhava por todo o mundo: o vírus Sars-cov-2, causador da doença Covid-19. Este vírus teve origem na cidade de Wuhan, na China. Tratava-se de um vírus causador de problemas respiratórios graves, que podia levar à morte (WHO, 2020).

Como sua disseminação foi muito rápida, a Covid-19 passou a ser considerada uma pandemia no início de 2020, pela Organização Mundial da Saúde, (WHO, 2020). Com isso, houve a necessidade de toda a população do mundo inteiro se resguardar até que se estudasse a vacina para combater este vírus. Muitos trabalhos se tornaram remotos, como foi o caso das instituições de ensino pesquisadas em Pernambuco e Minas Gerais.

As aulas passaram a ser executadas de forma síncrona e assíncrona. As escolas tiveram que se reinventar. Os professores abriram as portas de suas casas para seus alunos e ministraram as aulas através de plataformas online, vencendo desafios, trocando a lousa e o pincel por novos recursos tecnológicos (Almeida et al., 2020).

Com relação aos alunos, a situação também foi desafiadora. Distanciar-se dos amigos da escola, não foi fácil para muitos. Eles tiveram que se adaptar para assistirem suas aulas em diversas formas de ensino: alguns online, outros através de PETs (Programa de Ensino Tutorado), onde o aluno recebia o material de estudo e fazia as atividades correspondentes a ele, (Brasil, 2020, p.1).

O coronavírus acabou por devastar países ricos e pobres, fazendo com que os líderes passassem a buscar alternativas de forma independente e prematura, sem necessidade de recorrer à OMS (Reynolds, 2020). E, com isso veio um desconforto muito grande para muitos pais que tiveram que acompanhar seus filhos nos estudos, pois muitos pais não tinham o menor conhecimento didático e muitas vezes nem paciência para estudar com seus filhos. E, para piorar ainda a situação, muitos alunos não tinham condição financeira para colocar internet em casa, nem adquirir algum tipo de eletrônico para acompanhar as aulas. O ano de 2020 foi assustador, mas o vencemos, apesar de perdermos muitas vidas para a Covid-19 (Brasil, 2020, p.1).

Chega o ano de 2021. Estávamos todos mais amadurecidos e mais confiantes de que a vida voltaria ao normal. As vacinas começaram a dar sinais de surgimento, mas ainda não era hora de voltar com as aulas presenciais. Então, as aulas ainda continuaram de modo remoto, porém estávamos todos mais preparados e adaptados às tecnologias. Os professores se aprimoraram com relação às diversas ferramentas tecnológicas e passaram a tomar gosto por elas. Descobriram que poderiam diversificar suas aulas, torná-las mais atraentes, divertidas e enriquecedoras.

Araujo, (2005) afirma que o uso da tecnologia como ferramenta de aprendizagem deve ser utilizada com responsabilidade, pois o professor sempre deve prezar pela construção do conhecimento, devendo contemplar o desenvolvimento de habilidades cognitivas à medida que analisam, manipulam e acessam a internet.

A partir desse novo cenário a prática pedagógica foi reinventada e ressignificada em muitas escolas. Mas, o que 
mudou na proposta pedagógica das escolas? Como foi a readequação de planejamento, em especial no ensino de Ciências da Natureza? Como consolidaram o aprendizado, principalmente com as disciplinas que dependiam da sua prática? Medidas foram necessárias para que as atividades chegassem ao aluno. Mas, como a tecnologia pôde ajudar? No decorrer desse artigo vamos tentar explanar estas inquietações.

Assim, o presente trabalho visa analisar as concepções dos docentes acerca do ensino de Ciências da Natureza e suas dificuldades para o processo de ensino em sala de aula na perspectiva do ensino remoto. É objetivo específico investigar os planos de aulas dos professores, de modo a procurar conteúdo voltado à perspectiva do ensino remoto emergencial e quais ferramentas de assimilação de conteúdos estão sendo utilizadas para o processo ensino-aprendizagem dos alunos na pandemia.

\subsection{O ensino de ciências da natureza e a pandemia da covid-19}

A Base Nacional Comum Curricular - BNCC é um documento no qual as escolas devem se fundamentar para melhorarem seus currículos, projetos políticos e pedagógicos, entre outros documentos. Por ser um documento regimental, ele contém um complexo de aprendizagens indispensáveis que devem ser desenvolvidas por todos os discentes no decorrer do ensino básico, preservando o direito de aprendizagem de acordo com o Plano Nacional da Educação - PNE (Brasil, 2018). No aspecto geral, funciona conforme a condição do vínculo formado por suas especificidades em cada região (Mariani \& Sepel, 2020).

Conde et al., (2021) relatam através de sua pesquisa sobre a percepção de professores de uma das áreas de ciências naturais, que muitos desses profissionais ainda não conseguem se adequar com a realidade do período pandêmico por estarem inaptos aos usos das devidas tecnologias, apesar de alguns casos, alguns profissionais conseguirem executar algumas dinâmicas e conduzir suas aulas. Com isso podemos averiguar a ausência de conhecimentos essenciais sobre as técnicas de manipulação dessas ferramentas, o que aponta para uma falta de atenção para a formação inicial e continuada dos professores na atualidade em pleno período de isolamento social.

Essa pesquisa de Conde et al., (2021) e colaboradores ainda fomenta que:

Sugere-se para trabalhos futuros, a elaboração de estudos de caso em diferentes níveis de ensino da educação básica, que permitam compreender a percepção discente sobre o uso de jogos virtuais nas disciplinas de ciências naturais (química, física e biologia), seus desafios e suas contribuições para a melhoria e aperfeiçoamento do processo de ensino-aprendizagem, na perspectiva de desenvolver no aluno o letramento científico e a criticidade frente aos fenômenos naturais, sociais e tecnológicos (Conde et al., 2021,p. 10).

Soares Neto et al., (2021) contribui que para que haja qualidade na construção de conhecimento nesse universo virtual é necessário que se leve em consideração o aprimoramento com o manuseio do uso de tecnologias, ou seja, uma adaptação das práticas pedagógicas dos docentes e para isso é necessário que ocorram formações pontuais para não somente os professores, mas como os alunos e gestores escolares, para que juntos estejam aptos para a conjuntura do cenário do isolamento social.

É preciso que o professor vá além de métodos de ensino simples como a inserção de aplicativos nos dispositivos celulares dos alunos. É preciso instigar o interesse desses para que possam aprender determinados conteúdos de forma dinâmica. É preciso pensar em aulas onde o aluno raciocine e interaja com a ferramenta escolhida e/ou elaborada, podemos fazer com que os mesmos elaborem suas próprias conclusões sobre os conteúdos abordados (Soares Neto et al., 2021).

E, seguindo essa linha de raciocínio, Santos et al., (2021) colaboram em sua pesquisa sobre o uso da ferramenta de laboratório virtual no ensino de ciências naturais, destacando que os alunos se mostram uma inadimplência quanto a sua adaptação ao ensino remoto, visto que muitos resistem em acessar as plataformas diferentes com motivos como a ausência de tecnologias apropriadas, onde os mesmos alegam não possuir um celular atualizado.

Com base nessa premissa, segundo Santos e colaboradores, é necessário um roteiro didático elaborado previamente 
para o uso de laboratórios virtuais e/ou alternativas desse cunho. Mas, esses pesquisadores ainda contribuem que apesar dos alunos terem aprendido mais com a ferramenta de laboratório virtual, é preciso se pensar previamente em formas de melhor conduzir as situações, pensando na situação do ensino remoto, de forma a contribuir para um ensino-aprendizagem mais assíduo e eficaz (Santos et al., 2021).

E, ainda sobre o documento da BNCC se referindo à área de ciências da natureza, são oito as competências que relatam sobre o uso das tecnologias e dentre elas destacamos a 6,7 e 8 :

6. Utilizar diferentes linguagens e tecnologias digitais de informação e comunicação para se comunicar, acessar e disseminar informações, produzir conhecimentos e resolver problemas das Ciências da Natureza de forma crítica, significativa, reflexiva e ética.

7. Conhecer, apreciar e cuidar de si, do seu corpo e bem-estar, compreendendo-se na diversidade humana, fazendo-se respeitar e respeitando o outro, recorrendo aos conhecimentos das Ciências da Natureza e às suas tecnologias.

8. Agir pessoal e coletivamente com respeito, autonomia, responsabilidade, flexibilidade, resiliência e determinação, recorrendo aos conhecimentos das Ciências da Natureza para tomar decisões frente a questões científico-tecnológicas e socioambientais e a respeito da saúde individual e coletiva, com base em princípios éticos, democráticos, sustentáveis e solidários. (Brasil 2017, p.324).

Portanto, a ligação do Ensino de Ciências (anos finais) com a tecnologia está regulada, de forma mais abrangente, na terceira versão da BNCC, do ano de 2018. O documento mostra que o Ensino de Ciências nos anos finais do Ensino Fundamental é caracterizado pela exploração das vivências, saberes, interesses e curiosidades dos alunos sobre o mundo natural e material (Brasil, 2018), o que significa lançar mão do conhecimento científico e tecnológico, tornando possível, aos alunos, compreender os fenômenos e conhecer o mundo, o ambiente e a dinâmica da natureza.

\section{Metodologia}

O presente trabalho foi desenvolvido com professores da área de ciências da natureza atuantes no ensino médio de duas escolas, sendo uma escola pública, do estado de Pernambuco e uma escola particular do estado de Minas Gerais A amostra foi constituída de dez (10) professores, sendo quatro (4) de uma escola da rede particular do estado de Minas Gerais, em especial da cidade de Formiga (MG) e seis (6) professores de uma escola da rede estadual do estado de Pernambuco, em especial da cidade de Orobó (PE), a cidade escolhida foi devido ser a naturalidade dos autores. A amostra foi escolhida de forma aleatória, realizada através de sorteio, onde todas as escolas que ofertavam o ensino médio da cidade Formiga (MG), e da cidade de Orobó (PE), participaram do sorteio, utilizando como critério de exclusão a escola que se recu sasse a participar e as escolas que ofertam apenas o ensino fundamental.

Tratou-se de um estudo de caráter descritivo, quanti-qualitativo a partir de análises documentais. Andrade (2002) destaca que a pesquisa descritiva se preocupa em observar os fatos, registrá-los, analisá-los, classificá-los e interpretá-los, e o pesquisador não interfere neles. Gil (2008) completa dizendo que a abordagem descritiva possui como objetivo a descrição das características de uma população, fenômeno ou de uma experiência.

$\mathrm{Na}$ análise dos documentos, serviram de suporte para nosso estudo, os planos de aula e/ ou planejamento anual das disciplinas da área de ciências da natureza. Vale ressaltar que foram verificados os documentos correspondentes aos anos de 2020 - 2021, pois corresponde ao início e percurso da pandemia da Covid-19.

A pesquisa documental, segundo Sá-Silva et. al (2009, p. 5), "é um procedimento que se utiliza de métodos e técnicas para a apreensão, compreensão e análise de documentos dos mais variados tipos".

Também foi aplicado um questionário hospedado na plataforma Google Formulários, no qual estava inserido o termo de consentimento livre e esclarecido, que garantia o anonimato de todos os envolvidos na pesquisa. Todos os professores 
concordaram em participar da pesquisa. O questionário foi composto por 14 questões relacionadas à temática de ciências da natureza e o ensino na pandemia. Das 14 questões, 13 foram objetivas e 01 questão discursivas, com data de aplicação entre os dias 08 a 29 de outubro de 2021. A divulgação ocorreu através de convites enviados pelo aplicativo de mensagens instantâneas, (WhatsApp) pessoal dos professores, disponibilizado pela própria escola.

Diante do contexto, a partir das respostas do questionário, buscamos fazer uma análise sobre as principais dificuldades e alterações no ensino de ciências da natureza no atual cenário da pandemia do Covid - 19. A análise desse estudo parte da relação entre as teorias e narrativas sobre os métodos aplicados nas salas virtuais do ensino médio na área de Ciências da Natureza. As informações obtidas na pesquisa foram organizadas e analisadas mediante as figuras e tabelas construídas através do Google Formulários e Excel.

\section{Resultados e Discussão}

A priori, iremos dispor as informações coletadas nos questionários utilizados para as entrevistas com os docentes selecionados para esta pesquisa. Em seguida iremos discutir tais informações. A posteriori, postaremos em um quadro sobre as informações contidas nos planos de ensino desses profissionais de forma categorizada, seguida de uma discussão e, por tanto, poderemos lançar as devidas considerações finais.

No total, 10 professores responderam ao questionário, sendo 06 professores do estado de Pernambuco e 04 do estado de Minas Gerais, conforma a Figura 1 a seguir.

Figura 1: Cidade de atuação.

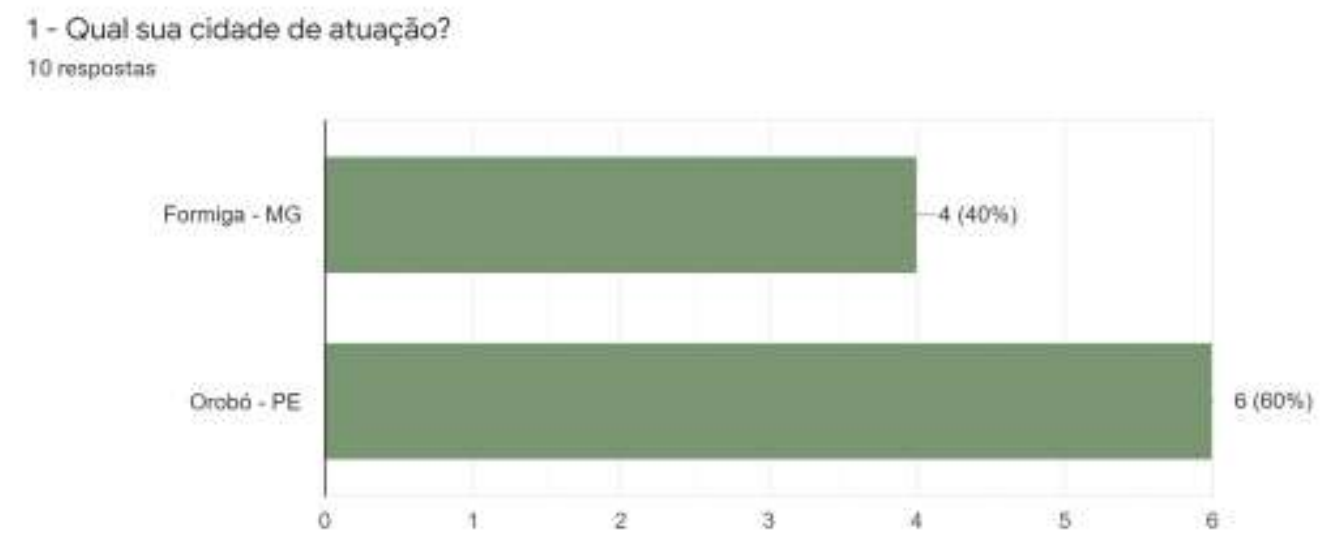

Fonte: Dados da pesquisa (2021).

De acordo com a Figura 2 abaixo, quando questionados sobre suas áreas de atuação, 01 professor diz ser da área de Ciências, 03 de Biologia, 05 de Química e 04 de Física. Na Figura 2, podemos observar que alguns professores atuam em mais de um conteúdo. 
Figura 2: Área de atuação dos professores de Ciências da Natureza.

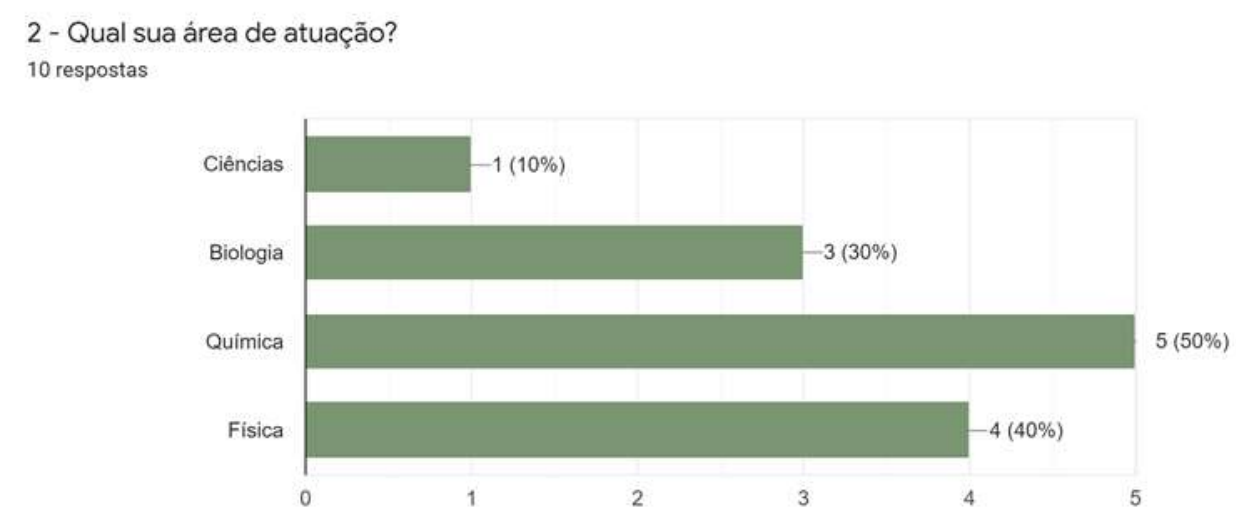

Fonte: Dados da pesquisa (2021).

Pelo fato de estarmos em uma pandemia, sem aulas presenciais, questionamos quais os principais meios utilizados para que as aulas e as atividades chegassem ao seu aluno, quais as plataformas utilizadas por esses docentes em suas aulas não presenciais.

Conforme a Figura 3 observamos que: 100\% afirmaram que usaram o WhatsApp - um aplicativo multiplataforma de mensagens instantâneas e chamadas de voz para smartphones. Além de mensagens de texto, os usuários podem enviar imagens, vídeos e documentos em PDF, além de fazer ligações grátis por meio de uma conexão com a internet,); $80 \%$ usaram o Google classroom, que segundo Schiehl e Gasparini (2016), o Google Classroom, também conhecido como Google Sala de Aula é um ambiente de sala de aula virtual onde professores e alunos se comunicam de forma online. O professor organiza suas turmas, disponibiliza materiais e acompanha seus alunos através dos trabalhos e atividades desenvolvidas. Além disso, todas as informações que são registradas pelos professores no aplicativo são enviadas aos estudantes, evitando assim, esquecimento ou falhas.

Também, 70\% fizeram uso do Google meet (um serviço de comunicação por vídeo desenvolvido pelo Google.), apenas $10 \%$ usou a ferramenta Zoom (Zoom Meetings é um programa de software de teleconferência de vídeo proprietário desenvolvido pelo Zoom Video Communications), 40\% usaram a plataforma ELOS (Plataforma de Comunicação ao Vivo), $30 \%$ trabalharam através de PETs (Programa de Ensino Tutorado - é uma das ferramentas do Regime de Estudo não Presencial, desenvolvido pela Secretaria de Estado de Educação de Minas Gerais). Ele foi ofertado aos alunos da rede pública como alternativa para a continuidade no processo de ensino e aprendizagem neste período em que as aulas estiverem suspensas por tempo indeterminado como medida de prevenção da disseminação da Covid-19) e 10\% utilizou algum outro tipo de aplicativo para as aulas. 
Figura 3: Principais meios utilizados para a entrega de atividades aos alunos.
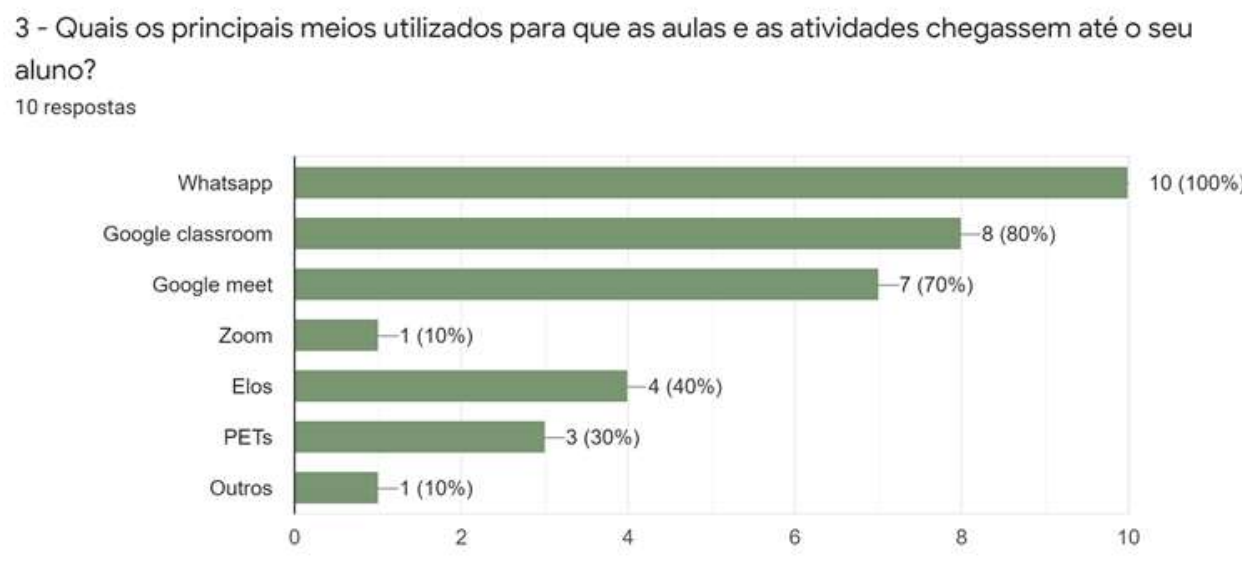

Fonte: Dados da pesquisa (2021).

Buscando saber quais recursos foram disponibilizados pela escola para a realização das atividades não presenciais, na Figura 4 observamos que $80 \%$ era material digital, tais como vídeo aulas, conteúdos organizados em plataformas de ensino e, $70 \%$ era material impresso, como livros, apostilas de conteúdos e de exercícios, onde o aluno ia até à escola para retirar este material. Apenas $10 \%$ disseram que a escola não disponibilizou nenhum recurso para a realização das atividades não presenciais.

Figura 4: recursos que foram disponibilizados pela escola para a realização das atividades não presenciais.

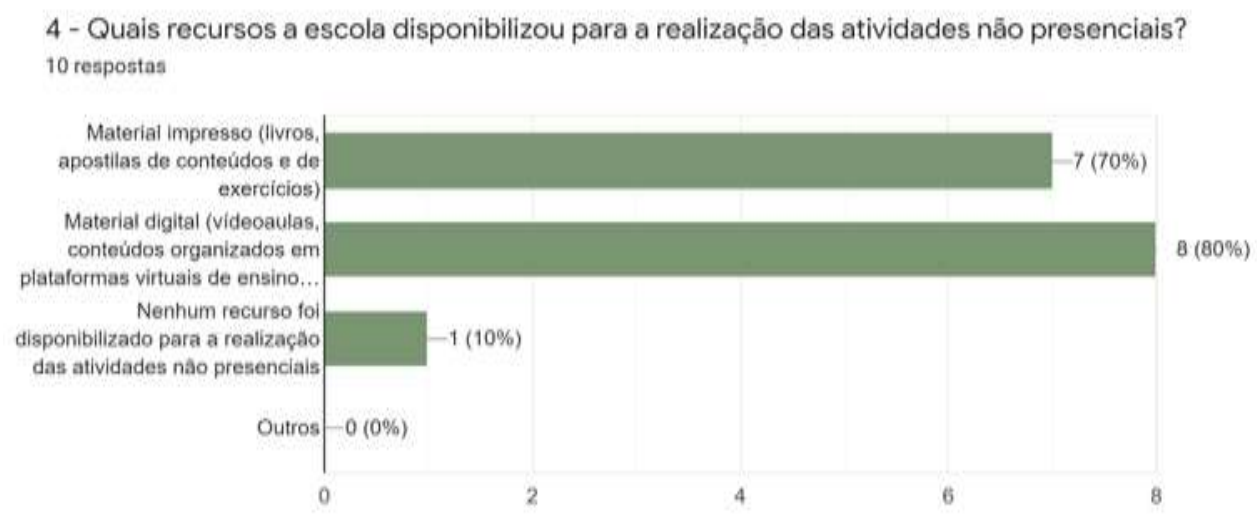

Fonte: Dados da pesquisa (2021).

Outro ponto importante da pesquisa foi saber qual foi a maior dificuldade encontrada pelos professores para auxiliar os alunos no regime especial de aulas não presenciais. A Figura 5 mostra que $90 \%$ desses professores afirmaram que a maior dificuldade foi o desinteresse por parte dos alunos; $60 \%$ deles afirmaram que a dificuldade de contato com o aluno também foi um problema encontrado; $40 \%$ disseram não ter conhecimento sobre ferramentas tecnológicas; $10 \%$ afirmaram que o fato de terem somente um aparelho para uso de diversas pessoas na casa foi uma dificuldade encontrada também; $10 \%$ dos docentes disseram que outro problema foi o fato de não terem computadores ou notebooks para ministrar as aulas e, por fim $40 \%$ informaram que encontraram outros tipos de dificuldades. 
Figura 5: maior dificuldade encontrada pelos professores para auxiliar os alunos no regime especial de aulas não presenciais.

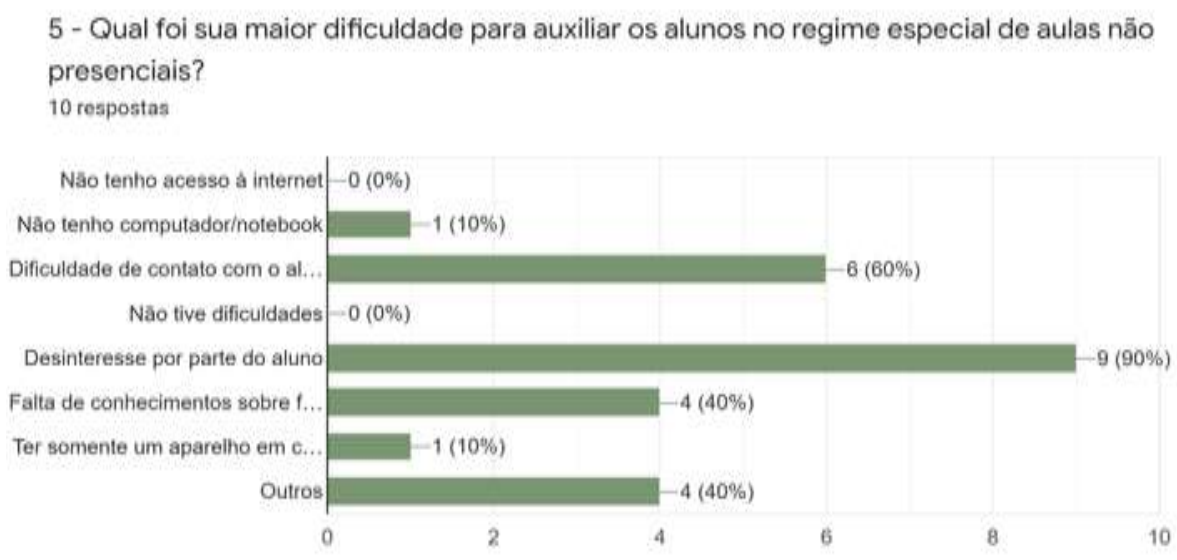

Fonte: Dados da pesquisa (2021).

O Ensino de Ciências, Biologia, Física e Química, quando intermediado pela experimentação torna-se indispensável na busca da compreensão e construção do saber científico. A importância da atividade prática é inquestionável no ensino, devendo ter um lugar de destaque na educação (Mello, 2010).

O profissional deverá lidar com recursos até então não utilizados em aulas presenciais, como: e-mail, web câmera, programas de conferência, redes sociais ensino (Ribeiro Júnior, et al., 2020).

Tais recursos são capazes de produzirem motivos de contratempos, provocando o desinteresse pelas aulas remotas, já que muitos docentes externam relutância ao fazer uso das tecnologias digitais tanto como uso diário quanto como instrumento de trabalho.

Por estarmos na pandemia, sem aulas presenciais, buscamos saber como as aulas práticas foram conduzidas e desenvolvidas, e, a Figura 6 mostra o resultado encontrado para esta pergunta.

Figura 6: A forma de como as aulas práticas no ensino de Ciências da Natureza foram conduzidas e desenvolvidas.

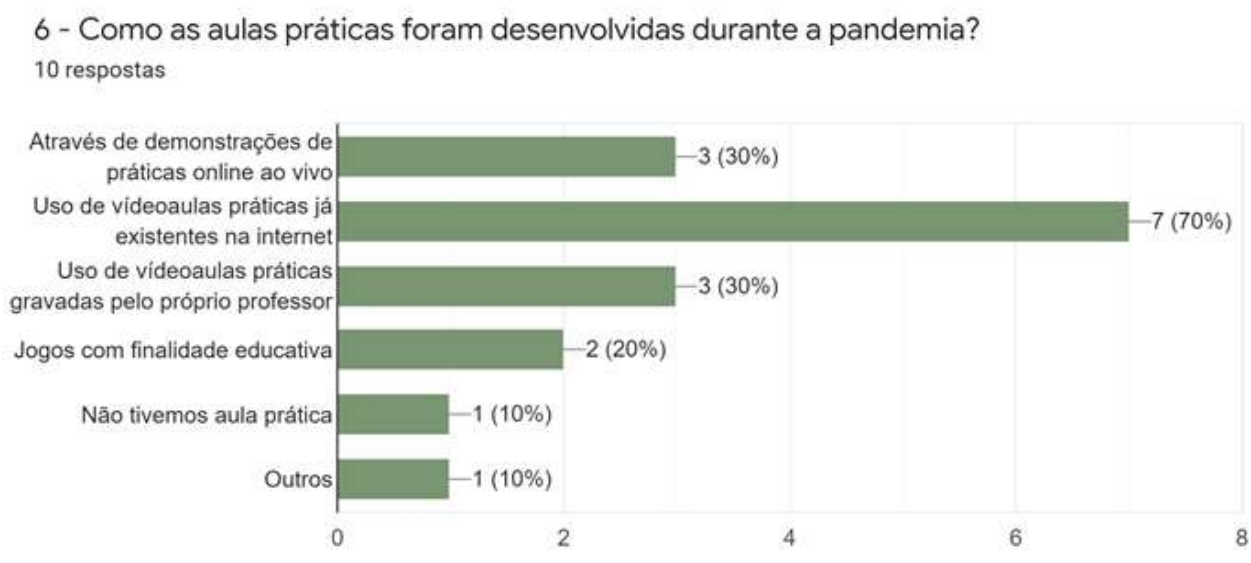

Fonte: Dados da pesquisa (2021).

Conforme mostra a figura acima, $70 \%$ dos professores enriqueceram suas aulas fazendo uso de videoaulas práticas já 
existentes na internet, enquanto que apenas 30\% faziam demonstrações práticas online, outros 30\% dos docentes gravaram seus próprios experimentos e os apresentaram aos alunos; $20 \%$ dos professores também optaram por jogos online com finalidades educativas, com o intuito de enriquecer o conteúdo; $10 \%$ disseram que não houve aula prática, apenas teórica e outros $10 \%$ utilizaram de outra forma para trabalhar a habilidade prática de seus alunos. Contudo, podemos observar que os professores utilizaram mais de uma forma para desenvolvimento prático de seus conteúdos.

Ribeiro Junior, et al. (2020) ressalta que tanto os professores quanto alunos e familiares não estão preparados para lidar com as aulas remotas e plataformas digitais. Todos necessitam de mais tempo para se adequar a esse tempo tão sensível e cheio de novidades a todo o momento, e também para se ajustar aos meios propostos para acompanhar o ensino remoto.

É preciso compreender que professores sem formação continuada para convívio com plataformas digitais podem provocar um abalo literalmente no ensino (Ribeiro Junior, et al., 2020). Nenhuma ferramenta virtual se compara com as aulas presenciais, o aprendizado é reduzido e o contato entre professor e aluno não é o mesmo, visto que, na sala de aula o feedback entre aluno e professor é direto e permanente.

O aluno também deve entender que as aulas remotas, demandam do seu comprometimento e interação para que haja essa troca de conhecimentos (Ribeiro Junior, et al., 2020). Sem o empenho do discente torna-se mais árduo trabalhar essa permuta de conhecimentos. Tanto o docente quanto o discente devem estar prontos para enfrentar tais obstáculos que a pandemia ocasionou para o meio escolar.

Diante de todo esse cenário de tamanhas dificuldades, perguntamos aos professores quais foram as principais dificuldades encontradas durante suas aulas.

Aqui, na Figura 7, podemos comprovar, juntamente com a pergunta de número 5 do nosso questionário, que, as maiores dificuldades encontradas pelos professores foram a falta de participação e devolutiva das atividades e o desinteresse por parte dos alunos.

Figura 7: As maiores dificuldades encontradas pelos professores.

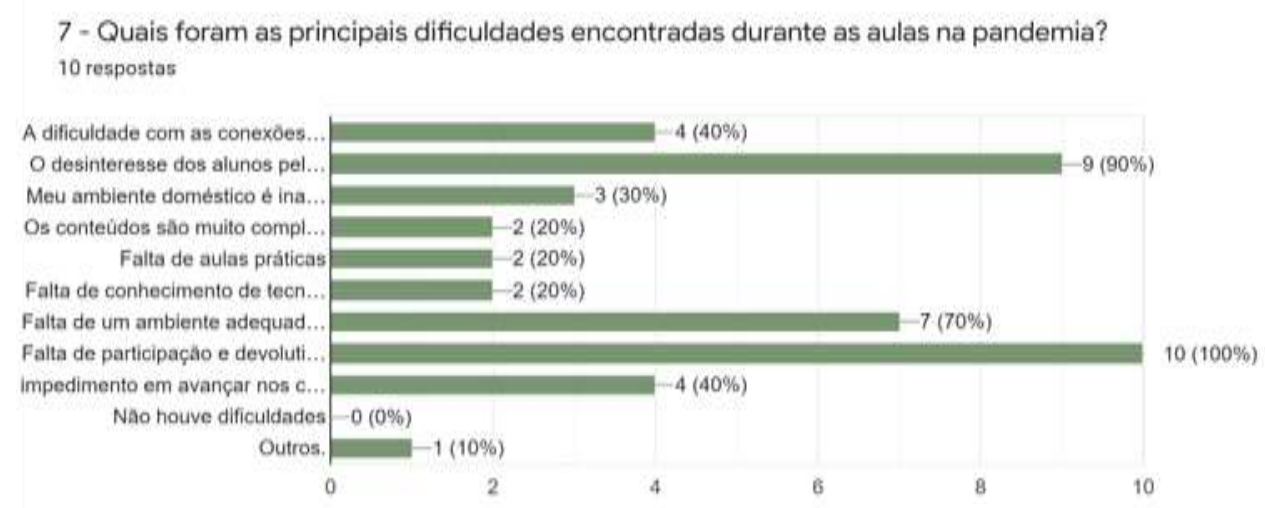

Fonte: Dados da pesquisa (2021).

Podemos ver também que $70 \%$ dos professores destacaram que houve falta de um ambiente adequado para realização das atividades e gravação das aulas. $40 \%$ dos docentes afirmaram que outro problema foi a dificuldade de conexões com a internet, tanto para o professor quanto para o aluno, com isso, houve impedimento em avançar nos conteúdos em decorrência dos estudantes não compreenderem os assuntos ministrados remotamente. Como a sala de aula foi transferida para as casas dos professores e alunos, 30\% deles disseram que o ambiente doméstico não era apropriado. Outras dificuldades, conforme 
afirmaram 20\% dos docentes, foram: conteúdos muito complexos para serem trabalhados virtualmente, falta de aulas práticas e falta de conhecimento de tecnologias digitais. Por fim, $10 \%$ afirmaram que outras dificuldades não citadas acima também foram encontradas.

Notamos que todos os docentes tiveram várias dificuldades ao mesmo tempo. Por isso, perguntamos se houve alteração no plano de aula durante a pandemia e, visualizamos, através da figura 8 , que $80 \%$ deles tiveram que alterá-lo e $20 \%$ não o fizeram.

Figura 8: Alteração no plano de aula durante a pandemia.

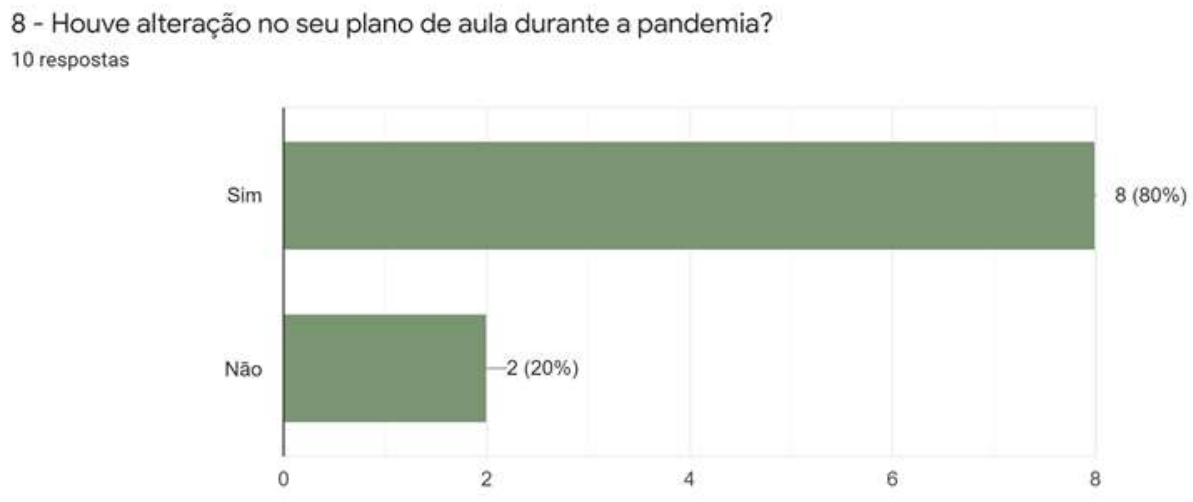

Fonte: Dados da pesquisa (2021).

Fomos mais longe ainda, pois sabemos que mais coisas poderiam ter mudado e não só o plano curricular. Por isso questionamos sobre o que mais mudou na proposta pedagógica curricular. E, unanimemente, $100 \%$ dos docentes, afirmaram que a metodologia de ensino teve que ser alterada, como mostra a Figura 9:

As metodologias ativas propõem algumas mudanças de paradigmas no sistema de educação, em especial ao comportamento de dois atores: discentes e docentes. Assim, o ensino e aprendizado passam a ser considerados processos interdependentes e de corresponsabilidade desses atores. Ao docente, cabe desligar-se do papel de detentor do saber e do modelo de ensino depositário, conforme denomina Freire (1996).

Em tempos de COVID-19, muitos dos docentes tiveram o convívio com o ensino online pela primeira vez, por isso é inegável a angústia quanto ao comprometimento dos alunos, principalmente nas metodologias ativas, onde o estudante é o protagonista do aprendizado. Para isso, o estudo em pequenos grupos e estudantes como criadores dos recursos de aprendizagem são estratégias relevantes. (Zayapragassarazan, 2020). 
Figura 9: Alteração na metodologia de ensino.

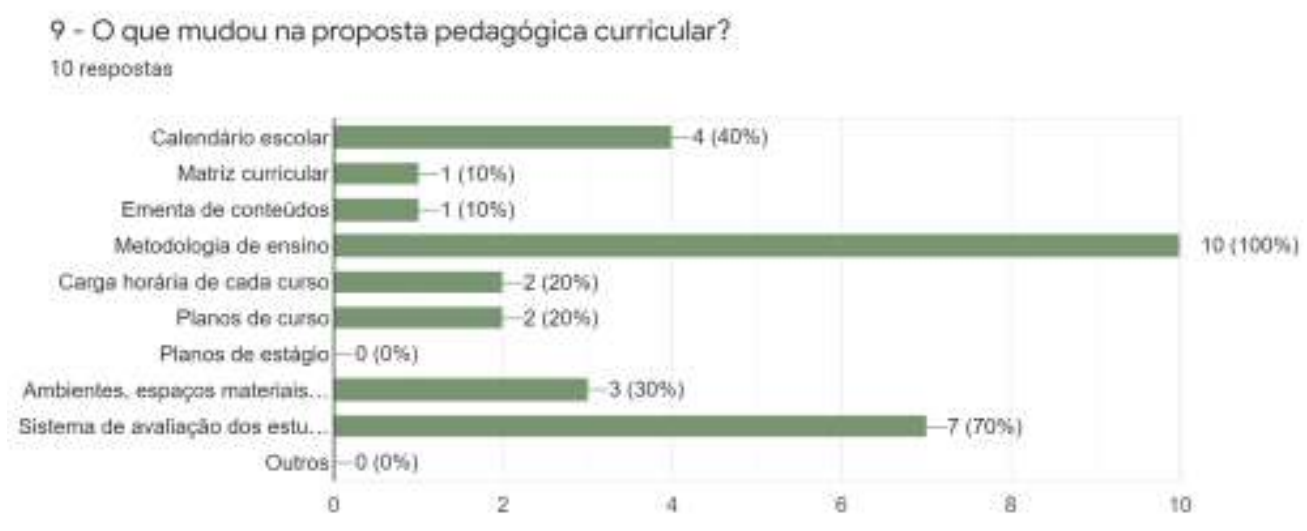

Fonte: Dados da pesquisa (2021).

Continuando a análise da figura acima, vemos que $70 \%$ dos docentes também tiveram seus sistemas de avaliações alterados; $40 \%$ alteraram o calendário escolar; 30\% alteraram os ambientes, espaços e materiais a serem utilizados para implementação da proposta curricular; $20 \%$ alteraram carga horária e planos de curso e $10 \%$ modificaram suas matrizes curriculares e ementas de conteúdo.

Diante de tantas modificações, questionamos como foi a readequação do planejamento? A Figura 10, a seguir, mostra que as respostas foram as seguintes: $70 \%$ fizeram uso de metodologias ativas de ensino e aprendizagem, conforme também destacamos acima quando na questão 9.

Sobre o fortalecimento da relação de parceria entre escola e família, 60\% dos docentes afirmam que foram feitas adequações; $50 \%$ se adequaram com relação à criação de avaliação diagnóstica e os programas de recuperação de aprendizagens e 30\% adequaram seus calendários escolares e atividades online para acolhimento sócio emocional de professores, alunos e famílias.

Figura 10: Readequação do planejamento para o Ensino Remoto Emergencial

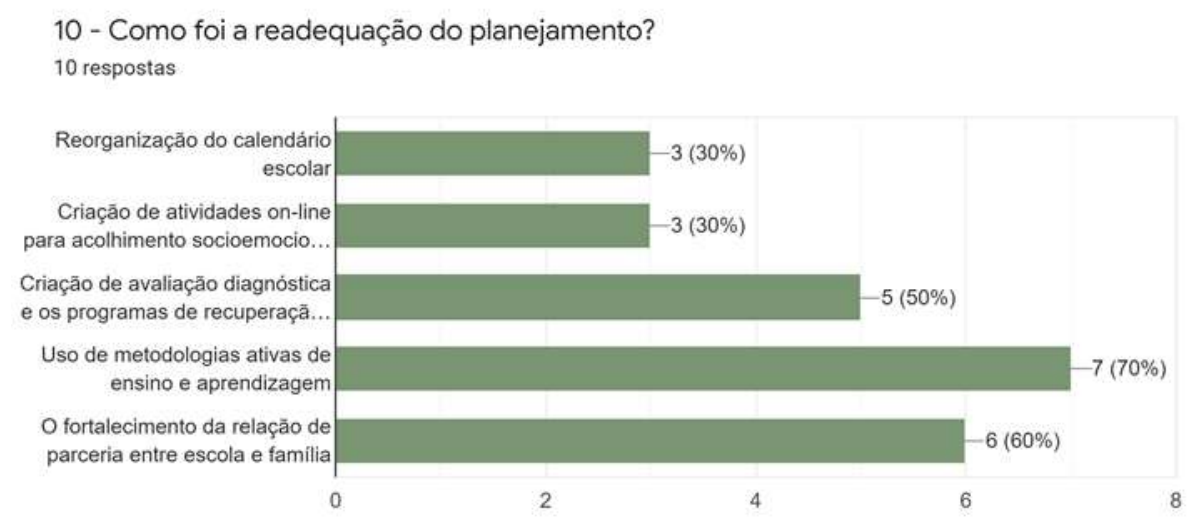

Fonte: Dados da pesquisa (2021).

Após todas essas mudanças, aulas dadas, questionamos como foram feitas as atividades avaliativas. Quisemos saber como esse aprendizado foi consolidado. Sabemos que não dá para comparar o aprendizado online com o presencial. Isso é 
impossível. Precisamos levar em conta suas peculiaridades, e o mesmo se aplica a avaliação. Há muitas variáveis que devem ser analisadas para que um processo avaliativo tenha resultados válidos e significativos. (Surry \& Ensminger, 2001).

Durante o ensino remoto emergencial precisa-se a priori considerar se os conhecimentos, habilidades e/ou atitudes pretendidas foram construídas. Do mesmo jeito com as questões relativas ao incentivo, disposição e comprometimento do aluno. Também é importante ressaltar que o momento é atípico e nunca vivido por nenhum dos atores envolvidos no processo de aprendizagem, assim o processo avaliativo deve ser dinâmico e flexível (Hodges et al., 2020).

Na Figura 11, observamos que $80 \%$ dos professores avaliaram seus alunos através de atividades personalizadas, criadas por eles mesmos ou que já estejam inseridas no próprio material didático. Também, com um percentual bem elevado, $70 \%$ disseram que a avaliação também foi processual, também chamada de "formativa" ou "contínua", avaliando habilidades e competências e não apenas conteúdo.

Notamos que $20 \%$ dos docentes fizeram uso de outros meios de consolidação do aprendizado e apenas $10 \%$ verificaram o aprendizado através de fóruns de discussão.

Figura 11: Processo de avaliação durante o Ensino Remoto Emergencial.

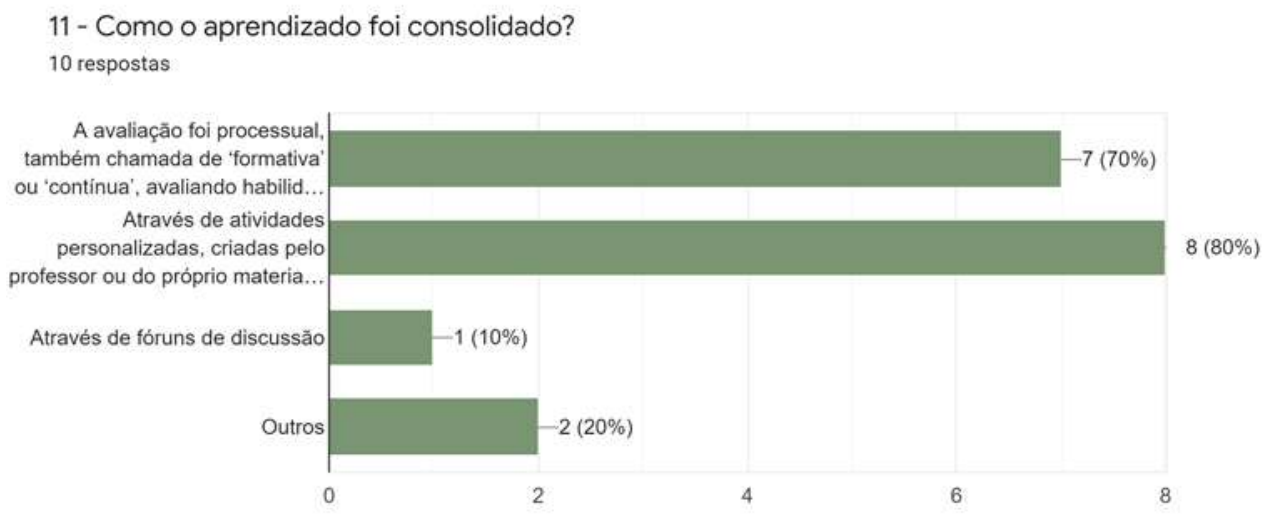

Fonte: Dados da pesquisa (2021).

Perguntamos aos docentes se eles, mesmo diante de tantas dificuldades, erros e acertos, consideram ter ampliado seus conhecimentos em tecnologias digitais e, se acreditam fazer uso delas pós-pandemia. $\mathrm{E}$, não esperávamos uma resposta diferente, pois sabemos que as TICs contribuíram e muito para o ensino remoto. A Figura 12 mostra que dos 10 professores, 09 disseram que sim, que continuarão a utilizá-las pós-pandemia e apenas 01 disse que não as utilizará mais e, provavelmente, não lhe acrescentou muito.

Como afirma (Masetto, 2013, p.8), "sem dúvidas a tecnologia nos atingiu como uma avalanche e envolve a todos. É notável e inegável que elas são uma das mais importantes aliadas do homem em todos os campos da vida e tem dominado de forma significativa as ações humanas em todos os âmbitos".

No ensino remoto fez-se o alicerce primordial para dar seguimento aos estudos e proporcionar as circunstâncias favoráveis ao ensino-aprendizagem sem abalar as normas de distanciamento social obrigatório, impedindo a disseminação do coronavírus que em tão pouco tempo tem dizimado milhares de pessoas. Santos (2002) complementa dizendo que:

O uso efetivo de tecnologia de informação para comunicar conhecimento requer que o contexto interpretativo seja compartilhado também. Quanto mais comunicadores compartilham conhecimentos similares, experiências e conhecimentos anteriores, maior será a eficiência da comunicação do conhecimento por canais de mediação digital 
(Santos, 2002, p.5).

Figura 12: Ampliação dos conhecimentos em relação às tecnologias digitais e, se possível uso no pós-pandemia.

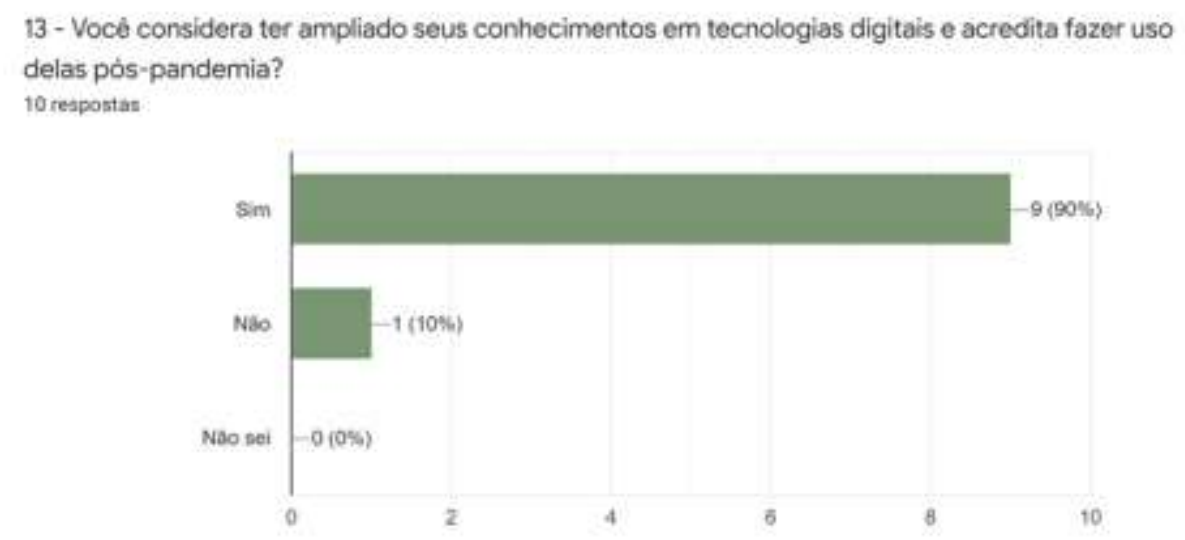

Fonte: Dados da pesquisa (2021).

As tecnologias digitais tornaram-se parte fundamental das escolas nos últimos anos, proporcionam acesso rápido a uma grande quantidade de informação, desta maneira modifica as formas de pensar e de construir conhecimentos, revelando a necessidade de pensar e discutir o uso das mesmas diante a realidade escolar (Schiehl et al., 2017).

Em nossa última pergunta, abrimos um espaço para que os docentes deixassem algum relato sobre sua prática pedagógica, caso achassem necessário relatar algo que não foi questionado nas questões anteriores. Apenas 03 deles fizeram uso deste espaço. Respostas estas que mostramos a seguir:

Professor 1: "Trabalho tanto na rede particular quanto na pública. Na rede pública, muito frequentemente, alunos têm acesso restrito à internet ou até mesmo nenhum acesso, o que dificulta a comunicação professor/aluno."

Professor 2: "Gostaria de enfatizar a falta de foco dos estudantes no período do retorno à escola com o ensino híbrido."

Professor 3: "As aulas remotas, provaram serem muito falhas. Os nossos alunos não desenvolveram uma responsabilidade ideal para o processo."

Solicitamos aos professores, na questão de número 12 de nosso questionário, que nos enviassem uma cópia de seu plano anual, como consta no quadro 1. Correlacionando o plano de aula anual com as respostas dos professores, foi feita uma análise de conteúdo que, de acordo com Bardin (2011, p.15), "a análise do conteúdo é um conjunto de instrumentos de cunho metodológico em constante aperfeiçoamento, que se aplicam a discursos (conteúdos e continentes) extremamente diversificados".

Sendo assim, para Bardin (2011), a análise de conteúdo, configura-se como um conjunto de técnicas de análise das comunicações, que faz uso de procedimentos sistemáticos e objetivos de descrição do conteúdo das mensagens. A princípio, os professores se mostraram despreparados para tal realidade do ensino remoto emergencial, não utilizando os princípios da Base Nacional Comum Curricular e, sem domínio de estratégias diferenciadas, de modo a facilitar o ensino-aprendizagem relacionado ao ensino de ciências da natureza. 
Quadro 1: Síntese dos planos anuais dos professores - item 12 do questionário aplicado (o "x" significa que atingiu a competência).

\begin{tabular}{|c|c|c|c|c|c|c|c|c|c|c|}
\hline & Plano 1 - A & Plano 2-A & Plano 3-A & Plano 4-A & Plano 5 -B & Plano 6 - B & Plano 7 - B & Plano 8 -B & Plano 9-B & Plano 10 - B \\
\hline $\begin{array}{l}\text { Ementa da } \\
\text { disciplina }\end{array}$ & $\begin{array}{l}\text { Não } \\
\text { entregue }\end{array}$ & $\begin{array}{c}\text { Não } \\
\text { entregue }\end{array}$ & $\begin{array}{c}\text { Documento } \\
\text { incompatíve } \\
1\end{array}$ & $\mathrm{x}$ & $\begin{array}{c}\text { De forma } \\
\text { sintetizada }\end{array}$ & $\begin{array}{c}\text { De forma } \\
\text { sintetizada }\end{array}$ & $\mathrm{x}$ & $\mathrm{x}$ & $\mathrm{x}$ & Não consta \\
\hline $\begin{array}{l}\text { Conteúdos } \\
\text { relacionados à } \\
\text { BNCC ou } \\
\text { competências }\end{array}$ & $\begin{array}{c}\text { Não } \\
\text { entregue }\end{array}$ & $\begin{array}{c}\text { Não } \\
\text { entregue }\end{array}$ & $\begin{array}{c}\text { Documento } \\
\text { incompatíve } \\
1\end{array}$ & ausente & $\begin{array}{c}\text { Algumas } \\
\text { informações }\end{array}$ & $\begin{array}{c}\text { Algumas } \\
\text { informações }\end{array}$ & ausente & ausente & ausente & $\begin{array}{l}\text { Não } \\
\text { consta }\end{array}$ \\
\hline $\begin{array}{l}\text { Formato de } \\
\text { aulas } \\
\text { (Síncronas/ass } \\
\text { íncronas) }\end{array}$ & $\begin{array}{c}\text { Não } \\
\text { entregue }\end{array}$ & $\begin{array}{c}\text { Não } \\
\text { entregue }\end{array}$ & $\begin{array}{c}\text { Documento } \\
\text { incompatíve } \\
1\end{array}$ & Síncronas & $\begin{array}{c}\text { Deixa } \\
\text { subentendid } \\
\text { o que de } \\
\text { forma } \\
\text { síncrona }\end{array}$ & $\begin{array}{c}\text { Deixa } \\
\text { subentendid } \\
\text { o que de } \\
\text { forma } \\
\text { síncrona }\end{array}$ & síncronas & síncronas & síncronas & $\begin{array}{c}\text { vídeo aulas, } \\
\text { mas não deixa } \\
\text { claro o } \\
\text { formato }\end{array}$ \\
\hline $\begin{array}{c}\text { Estratégias de } \\
\text { ensino para o } \\
\text { ERE }\end{array}$ & $\begin{array}{c}\text { Não } \\
\text { entregue }\end{array}$ & $\begin{array}{c}\text { Não } \\
\text { entregue }\end{array}$ & $\begin{array}{c}\text { Documento } \\
\text { incompatíve } \\
1\end{array}$ & ausente & ausente & ausente & ausente & ausente & ausente & Não consta \\
\hline Avaliação & $\begin{array}{c}\text { Não } \\
\text { entregue }\end{array}$ & $\begin{array}{c}\text { Não } \\
\text { entregue }\end{array}$ & $\begin{array}{c}\text { Documento } \\
\text { incompatíve } \\
1\end{array}$ & $\mathrm{x}$ & $\begin{array}{l}\text { Não deixa } \\
\text { claro } \\
\text { qual/quais } \\
\text { formas de } \\
\text { como } \\
\text { avaliar }\end{array}$ & $\begin{array}{l}\text { Não deixa } \\
\text { claro } \\
\text { qual/quais } \\
\text { formas de } \\
\text { como } \\
\text { avaliar }\end{array}$ & $\mathrm{x}$ & $\mathrm{x}$ & $\mathrm{x}$ & Não consta \\
\hline
\end{tabular}

Fonte: Dados da pesquisa (2021).

Com base nos nas informações coletadas acima, podemos observar que 2 (dois) professores não enviaram documentos compatíveis com o que foi solicitado para a composição dos resultados dessa pesquisa. Um (1) professor enviou um plano de aula, cujo documento também não é o solicitado.

A princípio, 4 (quatro) professores do ensino das ciências seguem utilizando planos de aulas compostos por ementas completas das disciplinas, o que é de extrema importância para se trabalhar os conteúdos categóricos nas aulas das referidas áreas de ciências.

Com relação à presente/ausente de conteúdos relacionados à $\mathrm{BNCC}$ ou competências, 5 (cinco) professores não apresentaram este tipo de conteúdo em seus documentos, enquanto que os dois (2) que apresentaram, não contemplaram informações precisas e dispostas de forma completa. Os demais não apresentaram de forma alguma.

Três (3) professores não contemplaram em seus planos os conteúdos relacionados ao formato das aulas, se síncronas ou assíncronas e quatro (4) deixaram claro que trabalharam com aulas síncronas até pelo tipo de atividade a ser aplicada em cada um dos planos.

Nenhum dos documentos apresentados está atualizado e/ou adequado ao trabalho na perspectiva do Ensino Remoto Emergencial (ERE), ensino remoto, aulas online ou algum desse tipo de proposta, ou seja, não tem nenhum preparo claro através das informações dispostas nos planos.

Quatro (4) planos de aulas esclareceram de forma completa a forma avaliativa de suas aulas, onde os professores destacaram os conteúdos atitudinais, as competências, habilidades e conhecimentos. Dois (2) não deixaram claro e em um (1) plano de aula não constou essa informação.

De acordo com Conde et al., (2021) os professores não conseguem adequar plenamente seu ensino para a realidade pandêmica. Isso vai de acordo com os questionários que fizemos aos professores nesta pesquisa e com seus planos de aula. 
Segundo a pesquisa de Soares Neto (2021) há uma necessidade de os professores aprimorarem seus conhecimentos a respeito do manuseio do uso de tecnologias, ou seja, uma adaptação das práticas pedagógicas desses docentes. Essas contribuições desse autor são compatíveis com a realidade apresentada nesta pesquisa.

\section{Considerações Finais}

A princípio, podemos destacar que, com base nas informações presente no quadro sobre os planos de ensino dos professores, observamos o quanto alarmante está a questão da falta de investimentos dos professores em estratégia de ensino adepta a realidade da perspectiva do Ensino Remoto Emergencial, aulas assíncronas, aulas online e demais que fujam do padrão tradicional de aula nos espaços formais de ensino.

Necessitamos de estratégias que sirvam de retaguarda ou como uma segunda estratégia caso seja preciso um distanciamento social entre todos os sujeitos envolvidos no sistema educacional.

Podemos também concluir que o fato de não constar nos planos de aulas as devidas informações sobre as estratégias de avaliação na maioria dos planos apresentados, constitui um dado alarmante, pois a avaliação segundo o BNCC e Leis de Diretrizes e Bases da Educação representa um elemento primordial para o progresso do processo de ensino-aprendizagem.

É notável o quão necessário é voltar os olhares para os professores e seus alunos, com relação à formação e melhores condições de trabalho dos mesmos, no ensino das ciências naturais. Há uma necessidade de haver esse investimento por parte das iniciativas governamentais, de modo a facilitar a interação e dinamismo na relação professor-alunos.

Não se pode falar em buscar novas alternativas e melhorar a formação docente sem se falar em melhor preparar os protagonistas do processo de ensino-aprendizagem, que no caso são os alunos. É preciso investigar as condições de acesso a equipamentos e internet de modo a tornar viável a manipulação e participação ativa do mesmo em caso de ensino remoto, híbrido ou "à distância".

Sendo assim, é preciso investir na formação inicial e continuada dos professores da educação básica, em prol do melhor preparo para o trabalho docente na atualidade. É de extrema importância o investimento em políticas públicas voltadas para esse tipo de formação, bem como no melhor amparo tecnológico da referida classe. Os alunos também necessitam estar aprofundados e preparados para um possível evento que obriga o distanciamento social, como foi o caso da pandemia da COVID-19.

Tendo por base as contribuições desta pesquisa, é possível concluir que há uma necessidade de reformular o processo de ensino-aprendizagem de ciências naturais na educação básica, na realidade do ensino remoto emergencial, de modo a erradicar com as lacunas que impossibilitam o ensinar e aprender com eficácia, podendo assim criar mais possibilidades para termos como produto final uma educação de qualidade, que caminhe e melhore juntamente com as condições de acesso à mesma, tanto por parte dos profissionais professores, quanto de seus aprendizes.

Essa pesquisa surge como pressuposto básico de modo a contribuir para eventualidades como o ensino remoto emergencial ou eventos similares, auxiliando no processo de ensino-aprendizagem para as ciências da natureza. Não menos importante, este trabalho serve como arcabouço teórico para divulgação científica, de modo a propor diversos debates envoltos ao tema.

\section{Referências}

Alencar Guedes, J. de (2021). Hidrografia e Google Earth: aula de campo virtual em tempos de pandemia. Ensino em Perspectivas, 2 (2), 1-12.

Almeida, E. G., Leite, K. L. F. L., Ferreira, L. S., \& Farias, M. S. (2020, outubro). Ensino remoto e tecnologia: uma nova postura docente na educação póspandemia. Anais do CONEDU-VII - Congresso Nacional de Educação. Maceió, Brasil, 10.

Araújo, R. S. (2005). Contribuições da Metodologia WebQuest no Processo de letramento dos alunos nas séries iniciais no Ensino Fundamental. In: 
MERCADO, Luís Paulo Leopoldo (org.). Vivências com Aprendizagem na Internet. (pp. 8-43). Maceió: Edufal.

Bardin L. (2011). Análise de conteúdo. Lisboa: (Edições 70) São Paulo: Livraria Martins Fonte.

Behrens, M. A., Moran, J. M., \& Masetto, M. T. (2013) Novas Tecnologias e Mediação Pedagógica (21a ed.) São Paulo: Papirus.

Brasil. (2018). Base Nacional Comum Curricular, BNCC. Aguiar, M. A. D. S., \& Dourado, L. F. A BNCC na contramão do PNE 2014-2024: avaliação e perspectivas. Recife: Anpae, 28-33.

Brasil. (2018). Instituto Nacional de Estudos e Pesquisas Educacionais Anísio Teixeira. Relatório do $2^{\circ}$ Ciclo de Monitoramento das Metas do Plano Nacional de Educação - Brasília, DF: Inep.

Conde, I. B.., Jacinto Jr., S. G., Silva, M. A. M. \& Veras, K. M. (2021). Perceptions of chemistry teachers during the COVID-19 pandemic on the use of virtual games in remote learning. Research, Society and Development. 10(10), e550101019070. 10.33448/rsd-v10i10.19070. https://rsdjournal.org/index.php/rsd/article/view/19070

Flauzino, V. D. P., Cesário, J. M. D. S., Hernandes, L. D. O., Gomes, D. M., \& Vitorino, P. G. D. S. (2021). As dificuldades da educação digital durante a pandemia de COVID-19. Revista Científica Multidisciplinar Núcleo do Conhecimento, 3(11), 05-32.

Gil, A. C. (2008). Como elaborar projetos de pesquisa. (5a ed). Atlas.

GIL, A. C. (2008). Métodos e técnicas de pesquisa social (6a ed.) Atlas.

Hodges C., Moore, S., Lockee, B., Trust. \& T., Bond A. (2020, março). The Difference Between Emergency Remote Teaching and Online Learning. Educause. Identificador: http://hdl.handle.net/10919/104648

Mariani, V. C. P., \& Sepel, L. M. N. (2020). Olhares docentes: caracterização do Ensino de Ciências em uma rede municipal de ensino perante a BNCC. Revista Brasileira De Ensino De Ciências E Matemática, 3(1). https://doi.org/10.5335/rbecm.v3i1.10022

Mello, J. F. R. (2010). Desenvolvimento de atividades práticas experimentais no ensino de Biologia: um estudo de caso (Dissertação Mestrado em Ensino de Ciências) - Universidade de Brasília, Brasília, Brasil.

Nogueira, J. V. D., \& Silva, C. M (2020) Conhecendo a origem do SARS-COV-2 (COVID-19). Revista Saúde e Meio Ambiente. Três Lagoas, 11 (2):115-124.

Reynolds, E. (2020, agosto 02). CNN - Cable News Network. Preso entre China e EUA, líder da OMS está no cargo que buscou a vida toda.

Ribeiro Júnior, M. C. Junior, M. C. R. Figueiredo, L.S., de Oliveira, D. C. A., Parente, M. P. M., \& dos Santos Holanda, J. (2020). Ensino remoto em tempos de covid-19: aplicações e dificuldades de acesso nos estados do Piauí e Maranhão. Boletim de Conjuntura (BOCA), 3(9), 107-126.

Santos, C. dos, Silveira Freitas, P. da, \& Marchezan Lopes, M. (2020). Anais Do Salão Internacional De Ensino, Pesquisa E Extensão, 12(1). Recuperado de https://periodicos.unipampa.edu.br/index.php/SIEPE/article/view/105870.

Santos, J.V.B., \& Monteiro, J.C.S. (2020). Educação e covid-19: as tecnologias digitais mediando a aprendizagem em tempos de pandemia. Revista Encantar Educação, Cultura e Sociedade - Bom Jesus da Lapa, 2, 01-15. http://dx.doi.org/10.46375/encantar.v2.0011.

Santos, Plácida L.V., Amorim da Costa, \& Sant'ana. Ricardo César Gonçalves. (2002) Transferência da informação: análise para a valorização de unidades de conhecimento. In: DataGramaZero - Revista de Ciência da Informação (3): 2.

Santos, R., Ribeiro, M, R. F., \& Carvalho, F. S. P. (2021, junho). Educação Online: aprender e ensinar em rede. Informática na Educação. CEIE-SBC. Secretaria de Educação do Estado de Minas Gerais (SEE/MG). (2020) Guia Prático para Professores.

Santos, S. E. de F., Jorge, E. M. de F., \& Winkler, I. (2021). Inteligência artificial e virtualização em ambientes virtuais de ensino e aprendizagem: desafios e perspectivas tecnológicas. Revista ETD - Educação e Temática Digital.

Sá-Silva, J. R., Almeida, C. D., \& Guindani, J. F. (2009, julho). Pesquisa documental: pistas teóricas e metodológicas. Revista Brasileira de História e Ciências Sociais, São Leopoldo, RS, Ano 1:(1).

Schiehl, E. P., \& Gasparini, I. (2016). Contribuições do Google Sala de Aula para o ensino híbrido. RENOTE, 14(2).

Soares Neto, J., Pinho, F. V. A. de., Matos, H. L., Lopes, A. R. de O., Cerqueira, G. S., \& Souza, E. P. de. (2021) Teaching technologies used in Education in the COVID-19 pandemic: an integrative review. Research, Society and Development, [S. 1.], 10 (1): e51710111974. 10.33448/rsd-v10i1.11974.

Surry, D.W., \& Ensminger D. C. (2001, jul-aug). What's Wrong with Media Comparison Studies? Educational Technology. 24(4): 32-35.

World Health Organization (WHO). (2020). Coronavirus disease (COVID-2019) situation reports WHO.

Xavier, R. A. G. (2019). FREIRE, Paulo. Pedagogia da autonomia: saberes necessários à prática educativa. São Paulo: Paz e Terra, 1996. Inter. Espaço: Revista de Geografia e Interdisciplinaridade, e10355-e10355.

Zayapragassarazan, Z. COVID-19: (2020, março). Strategies for Engaging Remote Learnersin Medic F1000 Research. 9(2): 273. 